\title{
The Economics of Formula 1
}

\author{
Arjun Kattepur, Victor Vostrikov \& Konark Goel \\ 'Being second is to be the first of the ones who lose' - Aryton Sena
}

\section{Introduction}

At the end of the 2008 season, Honda withdrew from F1 and planned to turn the attention of its 400 engineers to developing more environmentally friendly cars. In the wake of Honda's withdrawal, Toyota, and Sauber BMW are scheduled to withdraw at the end of 2009 as well. This begs the question of why these mainstream automobile manufacturers are backing out of F1.

The F1 market can be viewed as an oligopolistic market which comprises of a small number of strategically interacting players. The decisions made by one player in such a market affect the decisions of the others and vice versa. One of the characteristic features in an oligopolistic market is that firms can create a cartel by adopting a strategy of explicit or even tacit collusion, facilitated by their strategic interaction. The players involved in our case can be identified as the teams which compete in F1 such as Ferrari, McLarenMercedes, and Sauber BMW.

The Federation Internationale de l' Automobile is commonly known as the FIA is the overseeing regulatory body in F1. The FIA is responsible for sanctioning of funds and licensing F1 teams.

\section{Externality effects on the automobile industry}

Ever since its beginning $\mathrm{F} 1$ has had a significant positive impact on the automobile sector in general. As mentioned earlier, every team invests vast sums of money into the sport. Many of the latest technologies used in F1 such as stability systems, carbon composite brakes, 
dual clutch gear boxes, kinetic energy recovery systems (KERS) have been introduced into current automobile market.

Formula 1 has recently also started becoming a platform for globalization beyond its home in Western Europe with its presence represented by way of tracks in Hungary, Malaysia, China, Singapore, and Bahrain and by way of a team represented in India by Force India. This increases the prospect for technology transfer from the automobile manufacturers in developed countries to those of developing countries.

Most markets usually do not only enjoy positive externalities. The largest cause for concern from $\mathrm{F} 1$ is the opportunity cost of the huge amounts of resources that are being invested into the sport. In 2008, there was US $\$ 3.074$ billion being pooled into the sport by all teams which is close to the GDP of a small country. Also, as F1 is ultimately about speed, there is a lot of risk to the lives of the drivers involved. While the rate of fatalities has doubtless been reduced by innovation in safety, we have still observed the death of many racers in the past.

\section{Current scenario}

Formula one management or FOM controls the media distribution and the promotions for Formula one. The FOM provides partial investment to the teams and tracks to increase its popularity in locations where it is not known. The FOM maintains all the commercial rights of the teams along with all the media content related to Formula one.

In 1997, the FIA signed an agreement with all F1 teams known as the "Concorde Agreement". It stated that, out of the entire revenue generated over a season, most of it would be diverted to FOM and partially to be distributed equally among the teams. This was negligible compared to the resources being put in by the teams. Ever since the first Concorde agreement was signed there have been several amendments made to it till date. On July $28^{\text {th }} 2009$, a new agreement (6th Concorde Agreement) was signed where by the revenue would be distributed to meet the expectations of both parties. But here we should note that revenue is not the only thing that rivals are fighting for. The FIA as a governing 
body has the rights to change or set new rules such as budgetary or technical and organizational which are always reasons for a dispute. To secure F1's future in the current phase of the economic situation, the FIA introduced a budgetary cap system whereby the participating teams are supposed to spend no more than forty- million Euros a year with a few extra technical and design freedoms to the teams who nominated to use it such as movable wings in front and rear, an engine which is not subject to a rev limit (Formula1.com, 2009).

Some of the teams were not happy with this decision and came together and formed a cartel known as Formula One Team Association (FOTA). By forming a union they effectively increased their bargaining power and had a better chance at achieving their objectives such as getting a more favourable distribution of the revenues and influencing the technical regulations. The main threat that FOTA posed for the FIA was that it threatened hosting a separate F1 event. This shows that oligopolies gain market power similar to monopolists when they cartelize. The market power in this case is demonstrated as bargaining power.

A variety of recent external influences have had the potential to engender changes within this industry. One of the main external shocks recently has been the Global Financial Crisis (GFC) and its immediate impact on the automobile industry worldwide. As a result of the GFC, most automobile firms were faced with having to bear the significant expenses of participating in F1 while simultaneously facing shrinking revenues. The GFC has also had a deleterious impact on related industries such as financial providers and sponsors. As a natural response, once revenues started falling, some teams considered scaling back their investments or exiting the sport entirely (Formula1.net, 2008).

The question that arises is why the FIA insisted on introducing the new budgetary cap system in the upcoming season. The answer to this question is quite simple- the FIA would have taken the step keeping in the consideration of the shocks by the GFC and not letting the industry to go into corruption. 


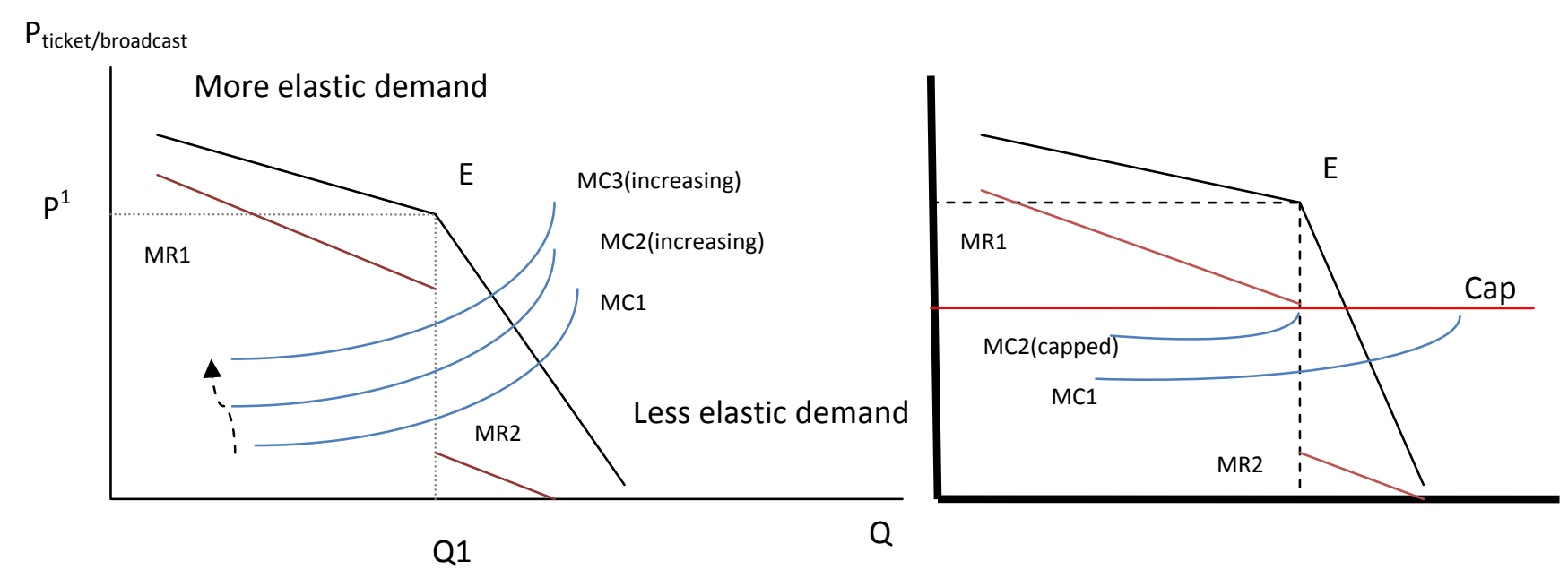

We can illustrate the problem by using the kinked demand curve framework for analyzing oligopoly behavior. Since the market is based on strategic interaction between firms, one market participant cannot change the price to enlarge its market share or get extra revenue without expecting retaliation from its rivals. Therefore, the price that exists in equilibrium in such a market suffices the condition of Nash equilibrium in that it is a best response for all participants. From equilibrium, if one firm were to lower its price in order to enlarge its market share, other oligopolists would react by reducing their prices as well to protect their market shares. This has the potential to escalate into a price war resulting in a decrease in overall revenues. Alternatively, if one firm were to decide to increase price in order to increase profit, other oligopolists may not reciprocate in changeing their price above the market equilibrium. Consequently, that firm would lose its market share due to having an uncompetitive price. These effects create a different elasticity for demand curve above and below the equilibrium giving it a kinked shape. The point at which the kink exists is also the point at which the oligopolistic market is in equilibrium. The kinked demand curve creates an associated discontinuity in the marginal revenue curve,essentially a gap that allows to add infinite number of marginal cost curves to exist 
for a given equilibrium price. Therefore, if marginal costs were to rise for the firms, price can conceivably still remain unchanged.

In applying this model to the F1 market, the producers can be seen to be the teams (or indeed their representative or cartel) and the FIA regulatory body. The output or final product is indeed the race event, which generates revenue for them. If we let $\mathrm{P}$ denote the price for a ticket to the event (indeed this could be seen to be any price charged to a F1 event consumer), $\mathrm{Q}$ be the race events, $\mathrm{P}^{1}$ becomes the equilibrium price for product, which is the race.

With the deepening on the global financial crisis, the returns from the F1 events started diminishing and perhaps even led some F1 producers to incur short term losses, particularly those teams that had to spend increasing amount of money to stay competitive with the front runners in $\mathrm{F} 1$.

As we already know, the prices are likely to be very sticky in F1 - in other words, the increasing cost cannot be passed on easily to consumers. If the event were to become any more expensive, the consumer could choose to watch the even on television, attend other events or, in the case of selling rights for broadcasting, the buyer would not be able to bear the costs and refuse to buy. An obvious way, therefore, to solve this problem or rising costs is to prevent them from escalating in the first place.

The second graph shows that setting a cap (red line) is a good strategy to survive. Exceeding the cap results in a loss, because the profits are surpassed by losses and being in the market become inefficient. This clearly explains the reason of why the FIA insisted on applying the budgetary cap for 2010 season. As a result of the introduction of the budgetary cap, the teams would not be pooling in large amount of money during such a financial downturn.

This also creates an opportunity for new teams to participate which may not have been in a position to compete otherwise. This can be confirmed with the entry of three new teams Campos Meta Team, Team US F1 and Lotus F1 Team for 2010 season. Also companies like Aston Martin are planning to enter the F1 market by 2012. 


\section{Concluding thoughts}

The conflict between the FIA and the FOTA has come to an end for now, with the $6^{\text {th }}$ Concorde Agreement being signed on the $29^{\text {th }}$ July 2009 and is said to be in effect till $31^{\text {st }}$ December 2012. The budgetary cap has been finalized at 40 million Euros rather than 30 million Euros. The cap system may be a good way to secure the future of the sport in an economic down turn as the current one. We also note that today most people and automobile manufacturers are shifting towards developing more environmentally friendly cars. Cars like the Honda Insight and the Toyota Prius are gaining a lot of popularity these days as is the smaller car segments, diesel-fueled cars, and full-electric vehicles. Have the automobile companies decided to focus on a totally different market or will F1 change lanes towards environmental friendly technologies as well? Let's wait and watch!

\section{References}

- Autosport.com, 2009, FOTA continues push to reduce cost, retrieved on August 20, 2009, www.autosport.com/news/report.php/id/73563

- F1FANATIC.CO.UK, 2008, Toyota has $\$ 445.6 \mathrm{~m}$ F1 budget, retrieved on August 20, 2009, www.f1fanatic.co.uk/2008/09/22/toyota-has-biggest-f1-budget-4456m

- Formula1.com, 2009, £40 million budget cap and 13 teams for 2010, retrieved on August 18, 2009, www.formula1.com/news/headlines/2009/4/9290.html

- Formula1.net, 2008, Confirmed: Honda withdraw from Formula1, retrieved on August 21, 2009, www.forumula1.net/2008/f1/lead_articles/confirmed-hondawithdraw-from-formula-one

- Nikkeibusiness online,2008, News and trends, retrieved on August 5, 2009, http://business.nikkeibp.co.jp/article/eng/20081215/180181/ 